\title{
Twitter, Team GB and the Australian Olympic Team: Representations of gender in social media spaces
}

Twitter is used by athletes, sporting teams and sports media to provide updates on the results of sporting events as they happen. Unlike traditional forms of sports media, online sports media offers the potential for diverse representations of athletes. The current study examined gender in social media coverage of the 2016 Olympic Games using a third wave feminist lens. The analysis focused on the Twitter pages of 'Team GB' and the 'Australian Olympic team' and the sports stories and images posted during the Rio Olympic Games. Despite a number of traditional differences in the ways that male and females were represented being present, such as the presence of 'active' images of male athletes accompanying sports stories and the presence of infantalization in the language used to represent female performers, this analysis demonstrated significant strides forward in terms of the quantity of coverage received by women in online spaces. It further highlights virtual platforms as dynamic spaces for the representation of women athletes.

Keywords: Twitter, Gender, Olympics, Social Media

\section{Introduction}

The arrival of Internet-based social media has largely transformed the space for media representation in sport; providing a dynamic space for sport communication. Sports media organisations have welcomed the opportunity to present news stories and live scores as widely as possible via such platforms. In particular, Twitter is used by athletes, sports teams and sports media outlets to provide updates on individual athletes, sporting clubs, sporting leagues and organisations and to report the results of sporting events as they happen. As Browning and Sanderson (2012) note, spaces such as Twitter have resulted in profound changes for sports journalists who now find themselves in direct competition with athletes and sports teams in breaking and reporting news. Social media platforms provide what print media could not, that is up-to-the-minute reporting on sport.

Traditional sports media such as newspapers, television and radio, have continually proved to neglect female athletes (Cooky et al. 2013, 2015; and Litchfield and Osborne 2015). Such platforms 
have traditionally represented women athletes with language and images that are predominantly heterosexualized, hyper feminized and infantilized (Litchfield 2015; Litchfield and Osborne 2015; and Messner and Cooky 2010). According to Jones (2006), the Internet is an interesting space which could offer an alternative representation of women through inclusive or empowering coverage, or could simply serve to consolidate the power of dominant groups present in other spaces. The use of social media to promote sports news and information provides an opportunity for sports media organisations to change this culture. In fact, social media platforms offer sports media focusing on women's sports a 'fresh start'. In the supposedly infinite space of online media, space for content is no longer a problem and diverse representations of gender and sexuality are possible.

The current study adopts a third wave feminist lens to examine the social media (Twitter) coverage of male and female Olympic athletes produced by two National Olympic Committees (NOC); the Australian Olympic Team (AOT) and the Great Britain Olympic team (Team GB) during the 2016 Olympic Games. The Australian Olympic team and the Great Britain team both have a proud history of participation and success at the modern Olympic Games. Sports stories and posts by both the AOT and Team GB were recorded during the 2016 Olympic Games $\left(5^{\text {th }}\right.$ August $-21^{\text {st }}$ August, 2016). In particular, this study investigates the gender representation found in these news stories, examining which athletes were the focus of posts, as well as an analysis of the language and images used alongside each Twitter post. Such an analysis provides a glimpse into the climate of online sports media platforms for female athletes, which to date remains an under examined space and more specifically examines how Olympic committees articulate gender through the representation of their teams in content published on social media platforms.

\section{Literature Review}

Despite increasing rates of participation and performance, globally persistent patterns in research continue to highlight disproportionate levels of reporting between male and female athletes in sports media (Bernstein 2002; Boyle 2009; Bruce 2016; Duncan, Messner and Willms 2005; Harris and Clayton 2002; Lumby, Caple and Greenwood 2009; Messner and Cooky 2010; Messner, Duncan and Cooky 2003; Pegoraro, Comeau and Frederick 2017; Phillips 1997; and Toohey 1997). As 
Tofoletti (2016) notes, the representation of women athletes can loosely be divided into research that surveys the quantity of coverage or the quality and subsequent representation of women across multiple forms of media. For example, Cooky and Messner (see Cooky, Messner, and Hextrum 2013; Cooky, Messner, and Musto 2015; and Messner and Cooky 2010) have investigated the culture of gender representation in televised sports media spaces for several decades. In their ongoing longitudinal research of sports news and highlights, shows on three network affiliates $(K A B C, K C B S$ and $K N B C$ ) and $E S P N$ 's SportsCenter program, they found that coverage of female athletes in these spaces has actually declined over the last decade (Cooky, Messner and Hextrum 2013). In the latest stage of this research by Cooky, Messner and Musto (2015), they explained that only 3.2\% of news stories on all the network affiliate sources and 2\% of overall airtime on ESPN's SportsCenter were devoted to female athletes.

In Australia, an Australian Sports Commission and University of New South Wales report on televised sports found similar results for women's sports and female athletes (Lumby, Caple and Greenwood 2009). This research found that $81.1 \%$ of sports coverage focused on male athletes and men's sports, $7.4 \%$ of sports coverage on 'other' (or gender-neutral topics), $2.8 \%$ of sports coverage was on mixed sports (males and females combined), and $8.7 \%$ of sports coverage was on women athletes or women's sports (Lumby, Caple and Greenwood 2009). Therefore, although slightly more encouraging than the results from the U.S. based study, televised sports news remains a male dominated space.

Gendered representation in the print media is not dissimilar to the results of televised sports (see Litchfield and Osborne 2015; Harris and Clayton 2002; Vincent et al. 2002). Litchfield and Osborne's (2015) study examined gender representation between Olympic and non-Olympic years in print media in Australia. They found that women were under-represented in the sports pages between 2008-2012 in Australia. The coverage of female athletes and female sports in non-Olympic years (2009, 2010 and 2011) was around 4.5\%. However, in Olympic years $(2008,2012)$, there was slightly more women focused sports stories, at around 14\% (Litchfield and Osborne 2015). 
When women do receive coverage through traditional media channels, their portrayal persistently proves to be gendered and laden in equalities (Pegoraro, Comeau and Frederick 2017). Traditionally, when sporting pursuits and performances are acknowledged in the sports media, female athletes can often be framed in feminine and heterosexual discourses and images (see Litchfield 2015; Litchfield and Osborne 2015; Lumby, Caple and Greenwood 2009). Thorpe, Toffoletti and Bruce (2017) acknowledge that female athletes "are routinely aestheticized, sexualised and trivialized" (361), they suggest that such representational tactics continue to position women athletes as inferior and this serves to limit or control their visibility in media spaces. With the advent of new media and social media it could be argued that there comes the potential for dominant representational regimes to be challenged and for female athletes to enhance their visibility and coverage on their own terms.

\section{Studies in online spaces}

Internet-based social media studies remain an emerging field of research; findings in this space have perhaps been hampered by the sheer vastness that constitutes virtual worlds or online spaces. Barlow (1990) created the term cyberspace to refer to the present-day nexus of computer and information technology networks to create a non-physical terrain created by computer systems. The Internet is recognized as the essential communication and information medium within our society (Castells 2010) and has over-taken many traditional mediums for consuming media. A large percentage of the research examining the sports media relationship with online spaces has focussed on websites and sports blogs (Eagleman, Burch and Vooris 2014) more recently exploration has extended to social media spaces.

Jones (2004) was one of the first researchers to look at gender representation in online spaces at the Olympic Games and has published work examining online media and gender in Australia for over a decade (see Jones 2004; 2006; and 2013). Her study (published in 2004) focused on ABC news online bulletins of the 2000 Sydney Olympic Games. This found that women competing in team sports received little recognition in the online sports media (Jones 2004). Jones' (2006) study investigated the online images of female athletes at the 2000 and 2004 Olympic Games. In particular, Jones (2006) investigated images accompanying news stories on ABC News Online, looking specifically at 'active' and 'passive' representations of female athletes (p. 116). According to Jones 
(2006), female athletes outnumbered males' online news images (Jones 2006, 118). Jones further explains that within these images, sportswomen were displayed in more active style images than passive roles (2006). In more recent work in 2013, Jones investigated four national online sports websites, including $A B C$ in Australia, $B B C$ in the United Kingdom, $C B C$ in the United States and TVNZ in New Zealand in relation to the gendered reporting of the 2008 Beijing Olympic Games. This research showed that $59 \%$ of stories were devoted to male athletes ( $41 \%$ to women), and $62 \%$ of photographs were devoted to male athletes (38\% to women) (Jones 2013, 251). Additionally, Jones explains that there was a greater focus on female athletes' personal relationships compared to male athletes $(2013,251)$. While these statistics and themes are not dissimilar to traditional representations of women athletes in the sports media, Jones' research has uncovered less disparity in the representation of men and women than in previous studies. Therefore, her work shows at the very least the potential for online sports reporting to represent women athletes (at least quantitatively) in numbers that are rarely seen in traditional sports media spaces.

Coche (2012) has also examined gendered sports coverage in online spaces. In her American based study, her research focussed on the Australian Open (tennis) coverage on the ESPN website (Coche 2012). Although the Australian Open features equal numbers of female and male competitors, Coche (2012) discovered that there were differences in the sports media attention awarded to the male and female athletes competing. Coche's (2012) research showed that within a total of 2155 articles analysed, $72 \%$ focused on men's tennis, $20 \%$ on women's tennis and $7 \%$ included stories that focused on both genders or the sports of tennis generally (79). Therefore, there was a large disparity in the gendered focus of articles for one specific tennis event with equal numbers of female and male participants. Burch, Eagleman and Pedersen's (2012) research explored websites from the 2010 Winter Olympic Games in relation to gendered coverage. Compared to traditional forms of sports media, their study showed that there was more equitable coverage of female athletes in online spaces (Burch, Eagleman and Pedersen 2012).

With the advent of web 2.0, the introduction of social media platforms that enable usergenerated content, has seen a shift in emphasis to prosumption rather than consumption in virtual spaces (Zajc 2015). Currently, professional sports teams and athletes utilise social media platforms 
such as Facebook or Twitter to keep fans up-to-date with news surrounding the sport, club or athlete. Sports media organisations also utilise these platforms to release sports stories and to provide live updates on sports matches thereby creating an interactive virtual sports experience (Kavanagh, Jones and Sheppard-Marks 2016). As a direct result, research has started to explore gender within the new media environment (Guerin-Eagleman and Burch 2016), yet findings here remain in their infancy.

Using social media platforms, athletes are thought to take a more active part in their publicpresentation and can therefore counteract their portrayal in the mass media (Reichart-Smith and Sanderson 2015). Social media further allows fans and athletes to experience a sense of connection, which can result in the formation of para-social relationships (Marwick and Boyd 2011) and can afford athletes some autonomy or ownership over their self-presentation or brand identity. Drawing on Goffman's (1959) work surrounding social interactions and self-presentation, the self-presentation strategies adopted by athletes in social media spaces has received attention in literature. Athletes are found to engage primarily in backstage performances both through written or text and photographic content. Backstage performances are those which take place when no audience or a familiar audience is present, and are considered less scripted or staged. In virtual spaces this occurs when athletes present their private lives and engage with fans or followers showing their non-guarded self (Pegoraro 2010; Hambrick, Simmons, Greenhalgh and Greenwell 2010; Lebel and Danlychuk 2012; GuerinEagleman and Burch 2016).

When linked to gender, Lebel and Danylchuk (2012) discovered that image construction was largely similar between males and females on the social media platform Twitter. There were however differences with the number of followers male athletes attracted when compared to females and the subsequent influence male athletes can establish in these spaces. Findings suggest male athletes have an advantage in online media were hegemonic values persist (Lebel and Danylchuk 2012). More recently, researchers have explored the representation of women athletes on visual platforms such as Instagram and Snapchat. Findings here point to a significant shift in these spaces, whereby women have ownership over their self-presentation and can start to challenge dominant gender stereotypes (Pegoraro, Comeau and Frederick 2017; Guerin-Eagleman and Burch 2016). Reichart Smith and Sanderson (2015) identified that when given control, female athletes are: "taking the opportunity to 
buck the trend of visual representations and present themselves as athletes first, females second" (354).

\section{New spaces, new rules and third wave feminism}

Bruce (2016) suggests that contemporary media spaces provide new opportunities for analysing the representation of sportswomen and believes that as a result, researchers in sports media must expand their interpretive frameworks in order to make sense of such coverage. In her paper 'New Rules for New Times', she suggests a critical shift whereby the rules that can be utilised to understand or represent patterns in media research to date are changing. Bruce (2016) recognises that while there were a number of older and/or persistent themes that still occur in the sports media coverage of female athletes, there are a number of current rules and new rules that are underrepresented in current research (see Table 1 below).

Table 1 - 'Rules' for media reporting of female athletes (adapted from Bruce 2016)

\section{Difference: Five Older Rules}

\begin{tabular}{ll}
\hline 1. Lower broadcast values & Reduced quality and quantity of coverage in women's sport \\
\hline 2. Gender marking & The practice of adding a gender modifier to women's sport \\
\hline 3. Infantilization & $\begin{array}{l}\text { The marginalizing practice of labelling adult sportswomen as } \\
\text { "girls", "young ladies" or using only their first names }\end{array}$ \\
\hline 4. Non-Sport-Related Aspects & $\begin{array}{l}\text { The practice of highlighting areas of the sportswomen's lives such } \\
\text { as family, personal life and their personality at the expense of } \\
\text { attention to their sporting achievements. }\end{array}$ \\
\hline 5. Comparison to men's sport & $\begin{array}{l}\text { Statements that lead to comparisons to male counterparts or men's } \\
\text { sports reinforcing the superiority of male sport as the norm to } \\
\text { which women's sport is judged. }\end{array}$
\end{tabular}

\section{Difference: Four Persistent Rules}

6. Sportswomen don't matter The discrepancy in the quantitative coverage of female athletes in the sports media (usually women average only $11 \%$ of sports media coverage)

7. Compulsory heterosexuality and appropriate femininity

8. Sexualization
Highlighting sportswomen's sexual and emotional relationships with males and the dominant discourses and images of traditional femininity Representing sportswomen through patriarchal discourses of idealized sexual attractiveness, prompting questions about objectification and whether the media focuses on them as athletes or sex objects Denying sportswomen appropriate recognition and prestige through highlighting positive descriptions of performance or images of female athletes and sport, whilst still reinforcing the gender hierarchy

\section{Similarity: Four Current Rules}




\begin{tabular}{ll}
\hline 10. Athletes in action & $\begin{array}{l}\text { The representation of sportswomen in action or competitive } \\
\text { settings }\end{array}$ \\
\hline 11. Serious athletes & $\begin{array}{l}\text { Portraying women as serious or legitimate athletes, recognising } \\
\text { athleticism, skill and performance accomplishments and women } \\
\text { 'legitimately striving for athletic success' (p.367). }\end{array}$ \\
\hline 12. Model Citizens & $\begin{array}{l}\text { Representing women athletes as successful national citizens rather } \\
\text { than female athletes. }\end{array}$ \\
\hline 13. Us and them & $\begin{array}{l}\text { Home nation athletes are presented as serious athletes and model } \\
\text { citizens and sports women from other nations are feminized or } \\
\text { subjected to sexualisation. }\end{array}$ \\
\hline
\end{tabular}

\section{New Rules for New Times: Two New Rules}

\begin{tabular}{ll}
\hline 14. Our Voices & $\begin{array}{l}\text { Sportswomen and their fans in control of what is written and } \\
\text { broadcast through new media. }\end{array}$ \\
\hline 15. Pretty and Powerful & $\begin{array}{l}\text { Sportswomen embrace femininity and physical competence as } \\
\text { complimentary rather than dualistic or opposing. }\end{array}$ \\
\hline
\end{tabular}

Media coverage of sports women in online media spaces, including social media, can simultaneously empower and oppress women. Bruce (2016) suggests that there is a link between third wave feminism and such a culture. She explains that:

Third wave feminism proposes that young women, no longer reliant on traditional media, understand the pleasure and power of popular culture, are telling their own multiple truths, and creating Internet-based sites and media that tell stories traditional media have ignored. (Bruce 2016, 368).

Third wave feminism emerged in the early to mid-1990s and was popularised by Rebecca Walker (activist and author) (Heywood 2006). Evans (2015) explained that third wave feminists have 'embraced individualism and diversity and sought to redefine what it means to be a feminist' (22). Third wave feminism offers a post-structural interpretation of gender and sexuality, and diverse cultural identities are focused upon.

In relation to sport, both Bruce (2016) and Heywood and Dworkin (2003) explain that third wave feminism has provided a conceptual framework to challenge feminist thought. Specifically, Bruce suggests that 'in sport participation, third wave feminism recognises, plays with and examines the simultaneously empowering and problematic elements of sport practice...' $(2016,368)$. Therefore, the use of third wave feminism has allowed a space to explain the multiplicity in sport media representations of female athletes. In particular, themes such as 'Athletes in action', 'Our voices' and 'Pretty and powerful' (Bruce 2016) provide an analysis tool to explain the simultaneous empowerment and oppression of female athletes using a third wave feminist critique. 
While there are examples of significant movements in terms of the quality and quantity of coverage for female athletes in social media spaces, there remains the potential for the continuation of the traditional representations of gendered sports media coverage. Social media has provided significant opportunity to challenge traditional modes of reporting and information sharing and has created opportunity for content to be produced by a variety of different stakeholders moving away from the notion of traditional sports journalism. During the Olympic Games, organisations such as National Sporting Organisations (NSO's) or National Olympic Committees (NOC's) release stories and provide live updates on performances and are a primary information source surrounding team performance. These non-profit organisations have the opportunity to benefit from interaction in this space, yet to date their adoption of social media has received limited attention in scholarly research.

It is evident that social media affords a unique space for interactive communication between sports organisations and consumers or followers of sport (Eagleman 2010; Pegoraro, Scott and Burch 2017). Social media has been identified as a valuable relationship marketing tool and can provide a space where sports fans connect and feel a sense of belonging (Eagleman 2013). More specifically, Naraine and Parent $(2016$; 2017) found that NSO's in Canada utilise social media to promote sports or events and share information, yet they further pointed to the lack of individuality in NSO's interaction on social media; communicating in relatively static ways, therefore under-utilising the potential for these spaces to develop brand identity. As Pegoraro et al. (2017) suggest, clear strategies concerning the focus of content shared on social media offers non-profit organisations such as NOC's strategic means to develop and maintain robust relationships with sports fans and consumers of sport. They highlight the power of virtual spaces such as Facebook for building positive brand images, increasing fan engagement and showcasing brand ambassadors. Importantly, these organisations need to have greater awareness of the content they produce and the subsequent impact it can have upon communities of followers. The current study extends the understanding of NOC's and their adoption of social media through critically examining how two Olympic committees articulate gender through the representation of their teams online communication published on the social media platform 
Twitter, during the 2016 Rio Olympic Games.

\section{Methodological Approach}

Two social media handles were the focus for this study (see Table Two). The Australian Olympic Team and Team GB provided up-to-the-minute reporting on their respective Olympic team throughout the duration of the games and provided a unique insight into team performance at these events. The Australian and Great Britain team were selected for a number of reasons. Firstly, given the duration of the Games and strategy for collection, there was a convenience element to data collection as the researchers resided in the United Kingdom and Australia which meant that real time surveillance linked to reporting could be achieved. Both teams have significant online presence and were taking teams which saw relative participation balance between male and female competitors at the Games. Finally, after adopting Hofstede's (1983) insights into cultural anthropology, these two nations are deemed culturally comparable. The collection of data took place during the 2016 Rio Olympic Games between the $5^{\text {th }}$ August, 2016 and the $21^{\text {st }}$ August, 2016.

Table 2. Social media sites used

\begin{tabular}{|l|l|l|}
\hline $\begin{array}{l}\text { Sports } \\
\text { organisation/team }\end{array}$ & Platform & Twitter address \\
\hline $\begin{array}{l}\text { Australian Olympic } \\
\text { Team }\end{array}$ & Twitter & @ AUSOlympicTeam \\
\hline $\begin{array}{l}\text { Great Britain and } \\
\text { Northern Island } \\
\text { Olympic Team }\end{array}$ & Twitter & @TeamGB \\
\hline
\end{tabular}

The method of online fieldwork was adopted for collection of archival data on the virtual platform of Twitter. This real-time micro-blogging-information network, connects users to the latest stories, ideas and opinions in the moment, as they happen (Twitter 2015). Data was recorded in the form of tweets posted on Twitter. At the time of data collection, these virtual posts were limited to 140 characters ${ }^{1}$; posts can include text, photo or video content.

\footnotetext{
${ }^{1}$ In September 2017 Twitter extended the length of tweets to 280 characters; this occurred after the data collection period.
} 
The tweets collected included a variety of information such as results of performances, live updates of matches or events, and general news and information relating to the 2016 Olympic Games; therefore, data included textual, audiovisual and photographic communication (Hodgetts and Chamberlain 2014). The notion of time is of interest in virtual research, whereby data or research artifacts can be collected in real time or as archival data after their posting (Tuncalp 2014). Data collection occurred at the same time every day on each site. Specifically, at three daily time points: during the first hour of Olympic coverage, the final hour of Olympic coverage and an additional hour in the middle of the day, per day on each site. Therefore, the data in this project contains three hours of sports news pieces on each site for each day during the Olympic Games, including both the opening and closing ceremony. The collection of archival data ensured that the data were unaffected by the actions of the researcher (Kozinets 2010); researchers did not interact within the space and instead acted as "lurkers" within this virtual environment.

Data was subject to both content analysis, to provide a description of what was present in this space; and a linguistic analysis to explore more deeply the nature of language present in the tweets. Content analysis is accepted as a means to quantitatively represent messages in mass media (Riffe, Lacy and Fico 2014). The gender breakdown of posts collected for each twitter site was analysed as well as recording the presence of images and conducting a descriptive analysis of each image that was associated with news stories. Gender were coded as male, female, combined or no gender focus. The gender focus was identified by reading the tweets and examining any media attached to it and then assigning the tweet to the prominent gender. Image analysis followed guidelines set out by Jones (2006; 2013), whereby images were analysed for depictions of active and passive poses. Active images include those taken within the competitive arena depicting dynamic movements and capture the athlete in action either competing, about to compete or post competition. Passive images capture the athlete in a motionless or static state. This could include head shots of the athlete posing for a camera or images unrelated to their competitive event away from the field of play. Tweets were examined for linguistic sexism linked to gender and sport played. Thus, the content of the language of the tweet was scrutinised for its wording and phrasing and the representation of athletes in this medium. Examples of linguistic sexism as demonstrated in existing research include mentions of the 
individual's appearance, relationships, links to emotions and infantalization of female performers. A number of themes were apparent and are included in the following section. Overall the results provide a 'gender breakdown' of data and from each site and two specific themes are explored: an analysis of the 'images of male and female Olympians'; and an analysis of the 'ambivalence and infantilization in reporting'.

\section{Results}

A total of 1455 Twitter posts were amassed during the collection period of the 2016 Rio Olympic Games. All of these posts focused on sports results, upcoming events or general information that surrounded the Olympic Games. Team GB were responsible for posting 679 sports news stories and the AOT posted 776 sports news stories. A breakdown of the total number of posts uncovered in the data collection is outlined in Table Three below.

Table 3 - Total number of posts

\begin{tabular}{|l|l|l|l|l|l|}
\hline Twitter site & $\begin{array}{l}\text { Total } \\
\text { number } \\
\text { of posts }\end{array}$ & $\begin{array}{l}\text { Male focused } \\
\text { posts }\end{array}$ & $\begin{array}{l}\text { Female } \\
\text { focused posts }\end{array}$ & $\begin{array}{l}\text { Posts focusing } \\
\text { on both male } \\
\text { and female }\end{array}$ & $\begin{array}{l}\text { Posts focusing } \\
\text { on gender } \\
\text { neutral topics }\end{array}$ \\
\hline $\begin{array}{l}\text { Australian } \\
\text { Olympic } \\
\text { Team }\end{array}$ & $n=776$ & $n=343$ & $n=322$ & $n=11$ & $n=100$ \\
\hline Team GB & $n=679$ & $n=338$ & $n=290$ & $n=21$ & $n=30$ \\
\hline TOTALS & 1455 & $n=681 ; 47 \%$ & $n=612 ; 42 \%$ & $n=32 ; 2 \%$ & $n=130 ; 9 \%$ \\
\hline
\end{tabular}

\section{Gender breakdown of posts}

There were a greater number (albeit a small amount) of male focused posts found on these two social media sites, compared to female focused posts. Overall, coverage of male athletes and events accounted for 681 of the posts (or 47\%) and female athletes and female sports accounted for 613 posts (42\%). This gender breakdown will be explained in further detail.

Team GB sent 366 athletes to compete in the Rio Olympic Games, including 202 male identified athletes (around 55\%) and 164 female identified athletes (around 45\%) (see BBC Sport 2016). On the Team GB Twitter site, $50 \%$ of posts focused on male athletes and male events and $42.5 \%$ of posts focused on female athletes and events, and $7.5 \%$ of social media posts focussed on 
both male and female combined or gender neutral topics. Team GB women athletes won eight out of their 27 gold medals awarded to the team. Therefore, in terms of the representation of gender in social media posts relative to participation numbers and (gold medal winning) performances of Team GB women athletes, (at least quantitatively) such figures are fairly representative of gender.

For the first time in Olympic history, the AOT sent marginally more female athletes than male athletes to the Rio 2016 Games. Australia's team consisted of a total of 419 athletes, which included 207 (or 49.4\%) male athletes and 212 (or 50.6\%) female athletes (ABC News 2016). This was not a deliberate attempt by the Australian Olympic Committee to ensure both male and female athletes were equally represented, but more of a last-minute change affecting the team numbers. Just days prior to the Games beginning, the Russian women's eights rowing team were disqualified from the Games, which left space for the Australian team to participate (ABC News 2016). In the social media analysis focused on the AOT, $44 \%$ of the posts focused on male athletes and events, $41.5 \%$ of the posts focused on female athletes and female events and $14.5 \%$ posts focused on both male and female athletes combined or gender neutral topics. Incidentally, the Australian women Olympic athletes won five of the eight gold medals for Australia. When participant numbers are combined with the relative success of the women's team, one might expect to see further Olympic coverage devoted to female athletes on the AOT Twitter site.

After all of the posts were analysed, there were two notable discrepancies within this data. Firstly, on closer examination of the images posted with each article, there was a gender discrepancy in relation to active and passive images and gender. Secondly, the language used in posts that focused on female athletes required a closer examination. Both of these considerations are explored below.

\section{Images of male and female Olympians}

An in-depth analysis was undertaken of the images posted with each of the news posts by both Team GB and the AOT. Table Four (Team GB data) and Table Five (AOT data) (found below) both outline the number of posts that contained images and the content of such images.

In relation to the posts found on the Team GB Twitter site, a significant number of posts were accompanied by an image (see Table Four below). In fact, $96.5 \%$ of posts focusing on male athletes featured an image. Additionally, 93\% of posts that focused on female athletes were accompanied by a 
photograph. Therefore, there were no major differences between genders in terms of the number of images accompanying a sports article on the Twitter site.

Table 4 - Team GB image analysis

\begin{tabular}{|c|c|c|c|c|c|}
\hline Category & Total & $\begin{array}{l}\text { Posts with } \\
\text { images }\end{array}$ & Active image & $\begin{array}{l}\text { Passive } \\
\text { image }\end{array}$ & $\begin{array}{l}\text { Gender } \\
\text { neutral } \\
\text { image }\end{array}$ \\
\hline Male focused & $n=338$ & $n=326$ & $n=228 ; 70 \%$ & $n=98 ; 30 \%$ & $n=0$ \\
\hline $\begin{array}{l}\text { Female } \\
\text { focused }\end{array}$ & $n=290$ & $n=270$ & $n=108 ; 40 \%$ & $n=162 ; 60 \%$ & $n=0$ \\
\hline $\begin{array}{l}\text { Gender } \\
\text { neutral focus }\end{array}$ & $n=30$ & $n=24$ & $\begin{array}{l}n=3 \text { (male) } \\
n=5 \text { (male } \\
\text { and female } \\
\text { combined) }\end{array}$ & $\begin{array}{l}n=5 \text { (male } \\
\text { and female } \\
\text { combined) }\end{array}$ & $n=11$ \\
\hline $\begin{array}{l}\text { Both male } \\
\text { and female } \\
\text { focus }\end{array}$ & $n=21$ & $n=20$ & $n=6($ male $)$ & $\begin{array}{l}n=10 \text { (male } \\
\text { and female } \\
\text { combined) } \\
n=1 \\
\text { (female) }\end{array}$ & $n=3$ \\
\hline
\end{tabular}

Pertinent to the focus on female athletes however, was the content of each of these images for Team GB. Male focused posts on the Team GB site were more likely to feature an active pose of a male athlete compared to a female athlete. In fact, $70 \%$ of posts that focused on male athletes, were accompanied by an image of male in an active pose and only $30 \%$ had an image of a passive sporting male. Passive focused images often featured athletes in medal ceremonies, engaged in a media interview or pictured with family members or other team members. Comparatively, $40 \%$ of posts focusing on female athletes were accompanied by an image of an active sporting female. This meant that posts focusing on female athletes at the Olympic Games were more likely to present females (around 60\% of the time) as passive participants in sport.

A total of $54.5 \%$ of posts that focused on male athletes found on the AOT Twitter site, featured an image (see Table Five below). Similarly, $56 \%$ of posts that focused on female athletes featured an image. Therefore, there were no notable differences between genders with posts that featured an image for the AOT posts. However, there were differences in the contents of the images relating to both male and female athletes. 
Table 5 - Australian Olympic Team Data

\begin{tabular}{|l|l|l|l|l|l|}
\hline Category & Total & $\begin{array}{l}\text { Posts with } \\
\text { images }\end{array}$ & Action image & Passive image & $\begin{array}{l}\text { Gender } \\
\text { neutral } \\
\text { image }\end{array}$ \\
\hline Male focused & $n=342$ & $n=186$ & $n=148 ; 80 \%$ & $n=38 ; 20 \%$ & $n=0$ \\
\hline $\begin{array}{l}\text { Female } \\
\text { focused }\end{array}$ & $n=322$ & $n=181$ & $n=126 ; 69 \%$ & $n=55 ; 31 \%$ & $n=0$ \\
\hline $\begin{array}{l}\text { Gender } \\
\text { neutral focus }\end{array}$ & $n=100$ & $n=91$ & $n=21$ (male) & $n=2$ (male) & $n=60$ \\
\hline $\begin{array}{l}\text { Both male } \\
\text { and female } \\
\text { focus }\end{array}$ & $n=11$ & $n=11$ & $\begin{array}{l}n=5 \text { (female) } \\
n=7 \text { (male) }\end{array}$ & $\begin{array}{l}n=3 \text { (female) } \\
n=1 \text { (male } \\
\text { and female } \\
\text { combined) }\end{array}$ & $n=0$ \\
& & & $n=1$ (female) & & \\
\hline & & & $\begin{array}{l}n=2 \text { (male and } \\
\text { female } \\
\text { combined) }\end{array}$ & & \\
\hline
\end{tabular}

Around $80 \%$ of male focused posts for the AOT featured an active image of a male athlete and $20 \%$ featured a non-active pose (or passive focus). Women athletes were framed in active poses in $69 \%$ of their posts and $31 \%$ of the time in passive poses. While this difference in active focused images between male and female athletes are not major, there are some differences of note in relation to some of these images. Specifically, when posts focused on combined male and female athletes, male athletes featured in active poses in $64 \%$ of the images. Comparatively, active poses of female athletes only featured $9 \%$ of the time.

Some instances of this occurring include three examples of news posts focusing on male and female swimming results and promoting upcoming swimming events. All three of these examples were accompanied by an image of a male swimmer in the pool (see 'Aussie swimmers set to make a splashing start', $6^{\text {th }}$ August, 2016; 'Find out what happened in the day three heats in the pool', $9^{\text {th }}$ August, 2016; and 'Swimming finals kick off tonight at 10pm (11am AEST)', 10 ${ }^{\text {th }}$ August, 2016). This was not just the case for swimming at the Olympic Games in 2016. Posts that focused on events where both male and female athletes were competing on the same days, such as Equestrian (a mixedgendered event), BMX, taekwondo and cycling also featured images of only active sporting males (see 'And we're off in eventing...', $9^{\text {th }}$ August, 2016; 'CYCLING - A ripping second day of track is just one hour away!, 13 ${ }^{\text {th }}$ August, 2016; 'Cycling: Scorching start for Aussies BMX campaign...', $18^{\text {th }}$ August, 2016; and 'Our taekwondo stars have hit the mat in Rio', $5^{\text {th }}$ August, 2016). 
Importantly, pairing images of active sporting males was also prominent with general sports news posts that focused on the Olympic Games. In a tweet that focused on the popularity of the golf simulator at the athlete's village, an accompanied imaged featured several active sporting males (see 'The golf simular is a hit with Aussie athletes during their downtime', $15^{\text {th }}$ August, 2016). Similarly, a tweet that focused on the results of all athletes on day 12 of the Games, an image of a male basketballer in action accompanied the link to an online article (see 'Catch up with how each of the Aussies in action fared on Day 12 at @Rio2016...', 19 ${ }^{\text {th }}$ August, 2016). Even when the tweet made reference to a news article which focused on female sports, there was no guarantee that the accompanying image would be of a female athlete. One particular article that focused on the results of a female athlete's performance in the pentathlon, featured an image of a male fencer (see 'Great start @ chloeesposito91 in modern pentathlon', 19 ${ }^{\text {th }}$ August, 2016).

Finally, a tweet linked to an article that featured the men's weightlifting event at the Games, focused predominately on the female dancers that preceded the event (see 'A bit of Samba to get us going before the \#Weightlifting...', $14^{\text {th }}$ August, 2016). The image accompanying this article showed scantily dressed females dancing in a sexualised manner. While the samba dance is culturally relevant to Rio de Janeiro and Brazil, the article could have been accompanied by an image of a prominent weightlifter or the weightlifting facilities. The dominant image of male athletes as active (particularly in posts that focus on both male and female events) supports the traditional view that sport is a male domain. Another way that this occurs is through the use of language used by the sports media (or in this case, a social media site focusing on sport). In relation to the current study, this will be explored below.

\section{Ambivalence and infantilization in reporting}

There are a number of positive examples of how female athletes can and should be represented by the sports media in this study. The vast majority of sports stories focused on the female athlete's sport and sports performance and not on how sexually attractive the athlete was or the sexuality of the athlete. There is also an equitable (on the most part) amount of coverage of female athletes and male athletes and there are also some accurate and positive images of sporting females. 
However, there are also several examples from both the AOT and Team GB Twitter sites, where female athletes were infantilised. Therefore, there are a number of examples of 'ambivalent' reporting of female athletes within this study not just in the representation of women through images but also the language adopted in reporting. 'Ambivalence' in contemporary sports media refers to a combination of positive images and reporting, along with the traditional undermining and negative images and reporting of female athletes, women's sporting competitions and women's sporting success (See Bruce 2016; and Wensing \& Bruce 2003). As a result, the reporter is able to point to positive descriptors and images of female athletes and sport, whilst still reinforcing the gender hierarchy.

A common way in which this occurred was through the infantilizing language used in Twitter posts and related stories. A specific example of this language is through the use of the word 'girl'. Both Twitter sites used the term 'girl' to describe female athletes commonly. The AOT site provided examples such as 'the girls making us proud'; 'our bronzed girls'; 'go girls'; 'bring it home girls'; and 'hold your heads high girls'(see 'Two from two for the women's rugby sevens - the girls making us proud', $7^{\text {th }}$ August, 2016; ‘Our bronzed girls @AnabelleSmith93 \& Maddison Keeney -3m synchro diving medal', $8^{\text {th }}$ August, 2016; 'SWIM: Coming up the women's medley relay heats, go girls! \#OneTeam', 13 ${ }^{\text {th }}$ August, 2016; 'Aussies have the ball. 53 secs to go. Scores level at 8-8. Bring it home girls!', 16 ${ }^{\text {th }}$ August, 2016; and 'Hold your heads high girls - Australia is proud! \#OneTeam \#Waterpolo', 16 ${ }^{\text {th }}$ August, 2016). In fact, even Australia's Chef de Mission labelled Australia's female athletes as 'girls'. When referring to the Australian Olympic women's team, Chiller was quoted as saying 'they're a great bunch of girls...' (see 'Chiller on the women's team: "they're a great bunch of girls"...', 9 $9^{\text {th }}$ August, 2016).

Similarly, there were a number of examples of the word 'girl' being used to describe female athletes on the Team GB Twitter site as well. Some of these examples included 'well done girls'; 'Girls, give yourselves a round of applause!'; 'Our girls are into the team final'; and 'our \#RugbySevens girls...' (see 'SO CLOSE! @ChloeMTutton finished 4th in 200m Breast', $11^{\text {th }}$ August, 2016; 'Semi finals...HERE WE COME! Girls, give yourselves a round of applause!', $15^{\text {th }}$ August, 2016; 'Our girls are into the team final, qualifying in 4th! ...', $7^{\text {th }}$ August, 2016; and 'Set your 
watches, our \#RugbySevens girls go for bronze at 10:30pm BST. \#BringOnTheGreat', $8^{\text {th }}$ August, 2016). Additionally, one particular example labelled English taekwondo gold medallist 'the little local girl' and thereby emphasised her size and gender (see 'Jade Jones: The "little local girl" who became a double Olympic Champion', $19^{\text {th }}$ August, 2016).

Wensing and Bruce (2003) suggest that infantilization of female athletes occurs by representing them as 'girls', 'young ladies' or using only their first names and as such 'tempers the symbolic threat posed by successful adult sportswomen' (388). By comparison, adult males are commonly referred to as men and are rarely referred to as 'boys' (Fink 2015; Wensing and Bruce 2003). Essentially, both the AOT and Team GB Twitter based posts adhered to the process of infantilization in their reporting of female athletes. This was due particularly to the labelling process of female athletes and female teams as 'girls'. Such labelling is not uncommon and remains a persistent method in describing (and devaluing) female athletes.

\section{Discussion}

It is pertinent that both of these Twitter sites are not operated by traditional media sources. Both sites are operated by major sporting organisations, the Australian Olympic Committee and the British Olympic Association. It is abundantly clear that both of these sporting organisations are promoting their own brand or own product, and that is, reporting on all of their representatives as best they can, is in their bests interests. Such reporting is not indicative of how traditional (and independent) sports media reporting operates.

This study shows that in a social media space (in this case Twitter), there is a simultaneous increase in the regular minimal coverage received by female athletes (that often occurs in traditional media), alongside a reinforcement of some of the traditional themes and messages found in the sports coverage of female athletes. If one was to compare research completed in traditional media spaces in Australia focusing on the Olympics (see Litchfield and Osborne 2015; Lumby et al. 2009), there was a significantly larger focus on female athletes in the current study. Team GB's data shows that the amount of Twitter space devoted to women was roughly commensurate with participation numbers, while the AOT's data was not. There was still (albeit small) more coverage dedicated to male athletes despite a greater number of female athletes participating and more women gold medallists. Such 
findings are consistent with Jones' (2013) research that focused on four national online sports websites, including $A B C$ in Australia, $B B C$ in the United Kingdom, $C B C$ in the United States and TVNZ in New Zealand in relation to the gendered reporting of the 2008 Beijing Olympic Games. Jones' (2013) research found that in these online media spaces, the traditional gap in sports coverage between male and female athletes is narrowing. She explained that $59 \%$ of stories were devoted to male athletes and $41 \%$ to women and that there is less disparity in the representation of men and women than in previous studies (Jones 2013, 251). As such, research shows that there is the potential for online sports reporting to represent women athletes (at least quantitatively) in numbers that are rarely seen in traditional sports media spaces. Online social media platforms provide a fertile ground for this potential to be realised.

It is also equally pertinent that Australian women won five of the eight gold medals for Australia. Australian women athletes and their performances were difficult to ignore. Therefore, the current study does represent a shift in the way women have traditionally been reported on in other media spaces. Billings et al. (2014) have noted this shift in television spaces at the 2012 Olympic Games. The $N B C$ 's primetime coverage of these Games spent more time discussing and analysing female athletes at the Games compared to male athletes (Billings et al. 2014). However, Billings et al. (2014) further explain that the increase in coverage of female athletes was due to the successful sporting performances of the Team USA women athletes (p. 53). So the performances of women at the Games play a major part in media coverage.

For both sets of data (particularly for Team GB), male athletes were more likely to be presented in an active pose and less likely to be presented in a passive pose compared to female athletes. Even when posts focused on both male and female athletes, this was the case - which reinforces the idea that males are more commonly associated with images of athlete and active. The lack of active females in the Team GB Twitter posts sends a subversive message that female athletes should be more commonly represented in images of a non-sporting nature. Moreover, one particular persistent theme (as outlined by Bruce 2016), was present in the data. That is, ambivalent reporting. In this case, there were a number of instances of infantilization. Therefore, although online sports media and social media platforms can and do offer unlimited space to report on all sport as it happens (both 
male and female sports), some of the persistent themes that exist in traditional forms of sports media carry over into online spaces. They are persistent and most importantly, engrained into how many may view sports in contemporary society, at least through the sports media. Such themes are echoed in the language and content adopted by NOC's during games time reporting.

The most relevant consideration in this study relates to third wave feminism. This study provides a small snapshot of the simultaneous empowerment and oppression that women athletes experience in sports social media representation. The use of third wave feminism allows us to analyse in multiplicity. In this case, multiplicity in gendered representation is apparent through the empowerment of women in overall media coverage (quantitatively) and through oppression (the infantilizing language used and the predominate promotion of male athletes as active participants in sport and females as passive - particularly on the Team GB Twitter site). Gendered coverage on these two Twitter sites can simultaneously reinforced the old rules of media coverage in the use of 'infantilization', the current rules of 'Athletes in action' and the new rule of 'Pretty and powerful' (Bruce 2016; and Wensing and Bruce 2003). Therefore, the data can only be understood in multiplicity and as such, the data provides a diverse representation of female athletes in social media settings.

\section{Concluding Comments}

There are a number of conflicting, competing and simultaneous experiences and narratives in the current study. The data for this study does not represent the narratives and representations necessarily found on other national Olympic team social media sites, nor does it necessarily represent the narrative on the AOT and Team GB Twitter sites for other major sporting events. However, the data outlines the representation of gender during the 2016 Olympic Games for both of these Twitter sites. Unlike a number of studies that focus on traditional media outlets and gender representation, the current study provides one of the first unique insights into the space of sports reporting on a NOC social media site.

It is vitally important to note that not one of these sports stories or posts explicitly focused on how sexually attractive or what sexuality these female athletes were (even though this might have 
been done implicitly). The focus of the bulk of these posts were on sport and sports performance.

Despite the language of 'girls' being used by both Twitter sites and the focus on passive images (on the Team GB site), overall, there has been a shift in how stories about women in sports are presented (at least in an online social media space). Bruce (2016) argues that, "the old rules of media coverage are changing...”. It could also be argued that sports media spaces that promote and represent female athletes in respectful and informative ways, are also emerging. In this case, the social media sites analysed are promoting their 'own' product, that is, athletes representing their country at the Olympic Games. Therefore, while some may suggest that such media coverage is biased, a significant lesson can be learnt from this narrative by other (and traditional) sports media organisations.

Organisations such as NOC's are shifting toward clear mandates concerning gender equality in sport, which has been represented in the formation of sports teams and through striving for equality in medal opportunities afforded to male and female athletes at the Olympic Games. Specifically, the International Olympic Committee (IOC) has championed gender equality in the Olympic movement with a pledge to ensure full gender equality in athlete quotas and medal events from the Summer Olympic Games in 2024 and Winter Games in 2026. With this in mind, there needs to be a deeper engagement concerning the content of the coverage NOC's provide; both in terms of volume, content and through greater attention to the language adopted in online communications. Organizing bodies of sport have the potential to use these platforms to bring equality in their coverage. As a result, the findings have the potential to influence media training for sports organisations, especially those who place value on equality but may fail to truly represent this through their virtual social media footprint.

\section{References}

$A B C$ News. 2016. "Rio 2016: Australia's team has more women than men for first time in summer Olympic history." ABC News Online, July 27. Accessed July 27, 2016. http://www.abc.net.au/news/2016-07-27/rio-2016-australian-team-more-women-than-men-forfirst-time/7665932

Australian Olympic Team Twitter site. 2016. @ AUSOlympicTeam. Accessed August 21, 2016. https://twitter.com/AUSOlympicTeam

Barlow, John. P. 1990. Crime and puzzlement: In advance of the law on the electronic frontier. Whole Earth Review [online]. Retrieved March 2018, from https://w2.e .org/Misc/Publications/John_Perry_Barlow/HTML/crime_and_puzzlement_1.html

BBC Sport. 2016. "Rio 2016: Great Britain and Norther Ireland's Olympic team." BBC Sport Olympics, July 19. Accessed July 19, 2016. http://www.bbc.com/sport/olympics/34813797 
Bernstein, Alina. 2002. "Is it time for a Victory Lap? - Changes in the Media Coverage of Women in Sport." International Review for the Sociology of Sport 37(3-4): 415-428.

Billings, Andrew. C., James R. Angelini, Paul J. MacArthur, Kimberly Bissell and Lauren R. Smith. 2014. “(Re)Calling London: The Gender Frame Agenda within NBC's Primetime Broadcast of the 2012 Olympiad." Journalism and Mass Communication Quarterly 91(1):38-58.

Boyle, Raymond. 2009. Power Play: Sport, the Media and Popular Culture. Edinburgh: Edinburgh University Press.

Browning, Blair and Jimmy Sanderson. 2012. "The positives and negatives of Twitter: Exploring how student-athletes use Twitter and respond to critical Tweets." International Journal of Sport Communication 5: 503-521.

Bruce, Toni. 2016. “New rules for new times: Sportswomen and media representation in the third wave." Sex Roles 74: 361-376.

Burch, Lauren M., Andrea N. Eagleman and Paul M. Pedersen. 2012. "New media coverage of gender in the 2010 Winter Olympics: An examination of online media content." International Journal of Sport Management 13: 143-159.

Castells, Manuel. 2010. The rise of the network society. Chichester: Wiley-Blackwell.

Coakley, Jay, Chris Hallinan, Peter Mewett Steve Jackson. 2009. Sport in society: Issues and controversies in Australia and New Zealand. Sydney: McGraw-Hill.

Coche, Roxane. 2012. 'Is ESPN Really the Women's Sports Network? A Content Analysis of ESPN's Internet Coverage of the Australian Open." Electronic News 7(2): 72-88.

Cooky, Cheryl, Michael A. Messner and Robin H. Hextrum. 2013. "Women play sport, but not on TV: A longitudinal study of televised news media." Communication \& Sport 1: 203-230.

Cooky, Cheryl, Michael A. Messner and Michela Musto. 2015. ““It's Dude Time!”: A Quarter Century of Excluding Women's Sports in Televised News and Highlights Shows." Communication \& Sport 3(3): 261-287.

Creedon, Pamela. 2014. "Women, Social Media, and Sport: Global Digital Communication Weaves a Web." Television and New Media 15(8): 711-716.

Duncan, Margaret Carlisle, Michael A. Messner and Nicole Willms. 2005. Gender in televised sports: News and highlights shows, 1989-2004. Los Angeles: Amateur Athletic Foundation of Los Angeles. Accessed from http://la84foundation.org/9arr/ResearchReports/tv2004.pdf

Eagleman, Andrea N. 2013. "Acceptance, motivations, and usage of social media as a marketing communications tool amongst employees of sporting national governing bodies." Sport Management Review 16: 488-497.

Eagleman, Andrea N., Lauren Burch and Ryan Vooris. 2014. "A unified version of London 2012: New-Media coverage of Gender, nationality, and sport for the Olympic consumers in six countries." Journal of Sport Management 28(4): 457-470.

Evans, Elizabeth. 2015. The Politics of Third Wave Feminisms: Neoliberalism, Intersectionality, and the State in Britain and the US. London: Palgrave Macmillan.

Fink, Janet S. 2014. 'Female athletes, women's sport, and the sport media commercial complex: Have we really "come a long way, baby"? Sport Management Review 18: 331-342.

Geurin-Eagleman, Andrea N and Lauren M. Burch. 2016. "Communicating via photographs: A gendered analysis of Olympic athletes' visual self-presentation on Instagram." Sport Management Review 19: 133-145.

Goffman, Ervin. 1959. The presentation of self in everyday life. New York: Anchor Books.

Hambrick, Marion E., Jason Simmons, Greg Greenhalgh and Christopher Greenwell. 2010. "Understanding professional athletes' use of Twitter: A content analysis of athlete tweets." International Journal of Sport Communication 3: 454-471.

Harris, John and Ben Clayton. 2002. "Femininity, Masculinity, Physicality and the English Tabloid Press-The Case of Anna Kournikova." International Review for the Sociology of Sport 37(3-4): 397-413.

Heywood, Leslie. 2006. The women's movement today: An encyclopedia of third-wave feminism. Westport: Greenwood Press.

Heywood, Leslie and Shari L. Dworkin. 2003. Built to win: The female athlete as cultural icon. Minneapolis: University of Minnesota Press. 
Hodgetts, Darrin and Kerry Chamberlain. 2014. “Analysing news media.” In The Sage Handbook of Qualitative Data Analysis, edited by Uwe Flick, 380-393. London: Sage Publications.

Hofsteade, Geert, 1983. "The cultural relativity of organizational practices and theories." Journal of International Business Studies 14(2): 75-89.

Jones, Dianne. 2013. "Online coverage of the 2008 Olympic Games on the ABC, BBC, CBC and TVNZ." Pacific Journalism Review 19(1): 244-263.

Jones, Dianne.2006. "The representation of female athletes in online images of successive Olympic Games." Pacific Journalism Review 12(1): 108-129.

Jones, Dianne. 2004. "Half the story: Olympic women on ABC News Online." Media International Australia 110: 132-14.

Kane, Mary Jo and Heather. D. Maxwell. 2011. "Expanding the Boundaries of Sport Media Research: Using Critical Theory to Explore Consumer Responses to Representations of Women's Sports." Journal of Sport Management 25(3): 202-216.

Kavanagh, Emma, J., Ian Jones and Lucy Sheppard-Marks (2016). "Towards typologies of virtual maltreatment: sport, digital cultures and dark leisure." Leisure Studies 35(6): 783-796.

Kozinets, Robert. 2010. Netnography. Doing Ethnographic Research Online. Thousand Oaks, CA: Sage.

Lebel, Katie and Karen Danylchuk. 2012. How tweet it is: "A gendered analysis of professional tennis players' self-presentation on Twitter." International Journal of Sport Communication 5: 461480.

Litchfield, Chelsea. 2015. "A media analysis of Ellyse Perry and the rise? of women's sport in Australia." Journal of Sporting Cultures and Identities 6(1): 11-22.

Litchfield, Chelsea and Jaquelyn Osborne. 2015. "Women in the Sports Pages: A Brief Insight into Olympic and Non-Olympic Years in Australia." International Journal of Sport and Society 4(4): $45-56$.

Lumby, Catharine, Helen Caple and Kate Greenwood. 2009. Towards a Level Playing Field: sport and gender in Australian media. Canberra: Australian Sports Commission. Accessed at https://secure.ausport.gov.au/_data/assets/pdf_file/0010/595567/ Towards_a_level_playing_field_-_Updated_Version.pdf.

Marwick, Alice., and danah boyd. 2011. "To see and be seen: Celebrity practice on Twitter." The International Journal of Research into New Media Technologies 17: 139-158.

Messner, Michael A. and Cheryl Cooky. 2010. Gender in Televised Sports: News and Highlights Shows, 1989-2009. Centre for Feminist Research, University of Southern California. Accessed from www.womenssportsfoundation.org/home/research/articlesandreports/media-issues/women-play-sports-but-not-on-tv.

Messner, Michael A., Margaret Carlisle Duncan and Cheryl Cooky. 2003. "Silence, Sports Bras and Wrestling Porn-Women in Televised Sports News and Highlights Shows." Journal of Sport and Social Issues 27 (1): 38-51.

Naraine, Michael, L and Milena Parent. 2017. "This is how we do it: A qualitative approach to national sports organisations' social media implementation." International Journal of Sport Communication 10: 196-217.

Naraine, Michael, L and Milena Parent. 2016. "Birds of a feather: An institutional approach to Canadian national sport organizations' social media use". International Journal of Sport Communication 9: 140-162.

Pegararo, Ann. 2010. "Look who's talking? - Athletes on Twitter: A case study." International Journal of Sport Communication 3: 501-515.

Pegoraro, Ann., Gina S. Comeau and Evan L. Frederick. 2017. "\#SheBelieves: the use of Instagram to frame the US Women's Soccer Team during \#FIFAWWC.” Sport in Society: DOI: 10.1080/17430437.2017.1310198

Pegoraro, Ann., Olan, Scott and Lauren Burch. 2017. "Strategic use of facebook to build brand awareness: A case study of two national sport organisations." International Journal of Public Administration in the Digital Age 4(1): 69-87. 
Phillips, Murray. 1997. "An Illusionary Image: A Report on the Media Coverage and Portrayal of Women's Sport in Australia 1996." Women and Sport Unit, Australian Sports Commission. Canberra: Goanna Print.

Reichart Smith, Lauren and Jimmy Sanderson. 2015. "I'm going to Instagram it! An analysis of athlete self-presentation on Instagram." Journal of Broadcasting \& Electronic Media 59(2): 342-358.

Riffe, Daniel., Stephen Lacy and Frederick Fico. 2014. Analyzing media messages using quantitative content analysis in research. London: Routledge.

Team GB Twitter site. 2016. @TeamGB. Accessed August 21, 2016. https://twitter.com/TeamGB

Thorpe, Holly, Kim Toffoletti and Toni Bruce. 2017. "Sportswomen and Social Media: Bring ThirdWave Feminism, Postfeminism, and Neoliberal Feminism Into Conversation." Journal of Sport and Social Issues 41(5): 359-383.

Toffoletti, Kim. 2016. "Analyzing media representations of sportswomen - Expanding the conceptual boundaries using a postfeminist sensibility." Sociology of Sport Journal 33(3): 199-207.

Toohey, Kristine. 1997. "Australian Television, Gender and the Olympic Games.” International Review for the Sociology of Sport 32(1): 19-29.

Tuncalp, Deniz. 2014. "(Re)Locating boundaries: a systematic review of online ethnography." Journal of Organizational Ethnography 3(1): 59-79.

Twitter. 2016. Accessed August 21, 2016. https://twitter.com/

Vincent, John, Charles Imwold, Vandra Masemann and James T. Johnson. 2002. A Comparison of Selected 'Serious' and 'Popular' British, Canadian, and United States Newspaper Coverage of Female and Male Athletes Competing in the Centennial Olympic Games: Did Female Athletes Receive Equitable Coverage in the 'Games of the Women?"' International Review for the Sociology of Sport 37(3): 319-335.

Wensing, Emma H. and Toni Bruce. 2003. "Bending the Rules: Media Representations of Gender During an International Sporting Event." International Review for the Sociology of Sport 38(4): 387-396.

Zajc, Melita. 2015. "Social media, prosumption, and dispositives: New mechanisms of the construction of subjectivity." Journal of Consumer Culture 15: 28-47. 